\title{
LA SENTENCIA SKANSKA DEL TJUE: EL CONCEPTO \\ DE "EMPRESA" EN LAS ACCIONES DE DAÑOS POR INFRACCIONES DEL DERECHO DE LA COMPETENCIA
}

\author{
THE CJEU'S SKANSKA JUDGMENT: THE NOTION \\ OF “UNDERTAKING” IN DAMAGES ACTIONS FOR \\ INFRINGEMENTS OF THE COMPETITION RULES
}

\author{
HeLMUT BRokeLmanN \\ MLAB Abogados S.L.P.
}

Recibido: 18.05.2020 / Aceptado: 03.06.2020

DOI: https://doi.org/10.20318/cdt.2020.5639

\begin{abstract}
Resumen: El artículo analiza la sentencia Skanska en la que el TJUE extiende los conceptos de "empresa" y "unidad económica", así como el principio de continuidad económica, desarrollados en su jurisprudencia en materia sancionadora por infracciones de los artículos 101 y 102 TFUE, a las acciones civiles de resarcimiento de daños y perjuicios. El TJUE declara que el propio artículo 101 TFUE, y no el Derecho nacional que regula las modalidades de ejercicio del derecho de indemnización, determina las entidades responsables de indemnizar los daños causados por una infracción de esta disposición.

Palabras clave: artículo 101 TFUE, concepto de empresa, principio de continuidad económica, demandas civiles de daños.

Abstract: The article analyses the Skanska judgment in which the CJEU extends the notions of "undertaking" and "economic unit" as well as the principle of economic continuity, developed in its case law concerning fines for infringements of Article 101 and 102 TFEU, to civil damages actions. The CJEU declares that Article 101 TFEU itself, and not national law which regulates the modalities of exercising the right to damages, determines the entities liable to pay damages for infringements of that provision.

Keywords: Article 101 TFEU; notion of undertaking; principle of economic continuity; civil damages actions.
\end{abstract}

Sumario: I. Introducción. II. Antecedentes en la jurisprudencia del TJUE. III. Los hechos del litigio nacional. IV. La Sentencia del TJUE. V. Valoración.

\section{Introducción}

1. La sentencia Skanska del Tribunal de Justicia de la Unión Europea (TJUE) ${ }^{1}$ constituye un nuevo paso en la "comunitarización" del Derecho civil y procesal de los Estados miembros. En respuesta a las cuestiones prejudiciales planteadas por el Tribunal Supremo finlandés en el marco de una demanda de daños por infracción del artículo 101 del TFUE, el TJUE se aparta de su anterior jurispru-

${ }^{1}$ Sentencia de 14 de marzo de 2019, Skanska, C-724/17, EU:C:2019:204. 
dencia sentada en Courage/Crehan y Manfredi ${ }^{2}$, según la cual las modalidades del ejercicio de estas acciones estaba reservada al Derecho nacional, para aplicar directamente el artículo 101 del Tratado $-\mathrm{y}$ concretamente el concepto de "empresa" de dicha disposición- para resolver una cuestión de sucesión de sociedades y legitimación pasiva que se planteaba en el litigio nacional.

2. Este artículo realiza un análisis crítico de esta sentencia y sus implicaciones para las demandas de daños por infracciones del Derecho de la competencia.

\section{Antecedentes en la jurisprudencia del TJUE}

3. Antes de exponer los hechos que dieron lugar a la cuestión prejudicial planteada por el Tribunal Supremo finlandés y para entender mejor la duda de interpretación del Derecho de la Unión que se suscitó ante el mismo en el litigio nacional, conviene recordar sucintamente la jurisprudencia del TJUE sobre el concepto de "empresa" en los artículos 101 y 102 TFUE.

4. Según una antigua y bien asentada jurisprudencia del TJUE³, el concepto de "empresa" infractora de las normas de competencia del Tratado - los artículos 101 y 102 TFUE — no se limita a la persona física o jurídica que haya cometido la infracción, sino que abarca toda la "unidad económica" de la que ésta forma parte. Con ello, la responsabilidad por las infracciones de los artículos 101 y 102 TFUE puede extenderse a sociedades matrices que controlen a la sociedad autora de la infracción ${ }^{4}$.

5. La consecuencia de esta jurisprudencia, que rompe con el principio de responsabilidad personal de la persona jurídica que ha cometido una infracción, generalmente reconocido en los ordenamientos jurídicos de los Estados miembros de la UE, es que la Comisión Europea puede imputar también a las sociedades matrices en sus expedientes sancionadores e imponer multas en aplicación del artículo 23 del Reglamento 1/2003 $3^{5}$ también a dichas matrices, que serán responsables solidarias junto con la filial infractora. Aunque las infracciones de los artículos 101 y 102 TFUE sean cometidas por "empresas" así definidas, las sanciones que la Comisión impone en virtud del artículo 23 del Reglamento 1/2003 deben dirigirse a personas concretas (físicas o jurídicas, comúnmente sociedades de capital) a efectos de su notificación y ejecución.

La consecuencia última de todo ello es que las multas que impone la Comisión no quedan limitadas a un máximo del $10 \%$ del volumen de negocios de la sociedad que propiamente haya cometido la infracción, sino que pueden ascender hasta el $10 \%$ del volumen de negocios total del grupo (en el sentido del artículo 42 de nuestro Código de Comercio) al que pertenece la sociedad infractora. De no ser así, las empresas podrían cometer sus infracciones de las normas de competencia - la participación en un cártel, por ejemplo - a través de pequeñas filiales con un volumen de negocios reducido, lo cual limitaría considerablemente el importe de las multas que pudiera imponer la Comisión y, con ello, el consiguiente efecto disuasorio de las mismas.

6. Esta jurisprudencia fue reforzada mediante la creación jurisprudencial — conocida como "regla Akzo" - de una presunción de control según la cual puede presumirse que una matriz que posee la totalidad del capital de una sociedad infractora ejerce una "influencia decisiva" sobre su filial, de modo que puede presumirse que ambas forman parte de una misma "unidad económica" y, por tanto, de una misma "empresa" a efectos de la aplicación de los artículos 101 y 102 TFUE. Aunque se trate de una presunción

\footnotetext{
${ }^{2}$ Sentencia de 20 de septiembre de 2001, Courage/Crehan, C-453/99, EU:C:2001:465 y Sentencia de 13 de julio de 2006, Manfredi/Lloyd Adriático Assicurazioni, C-295/04 a C-298/04, EU:C:2006:461.

${ }^{3}$ Sentencia de 12 de julio de 1984, Hydrotherm, 170/83, EU:C:1984:271.

${ }^{4}$ Ver, por ejemplo, Sentencia de 10 de abril de 2014, Siemens Österreich, C-231/11 P a C-233/11 P, EU:C:2014:256, apdo. 45.

${ }^{5}$ Reglamento 1/2003 de 16 de diciembre de 2002, relativo a la aplicación de las normas sobre competencia previstas en los artículos 81 y 82 del Tratado, DO L 1 de 4.1.2003, ELI: http://data.europa.eu/eli/reg/2003/1/oj.

${ }^{6}$ Sentencia de 10 de septiembre de 2009, Akzo Nobel, C-97/08 P, EU:C:2009:536.
} 
iuris tantum, en la práctica ha resultado muy difícil, por no decir imposible, refutar esta presunción mediante una prueba de que a pesar de controlar el $100 \%$ del capital de la filial ésta habría desempeñado una conducta autónoma e independiente de su matriz al cometer la infracción del Derecho de la competencia. Posteriormente esta presunción se ha extendido a supuestos de control con participaciones de capital inferiores al $100 \%{ }^{7}$. En la práctica, esta presunción ha venido a facilitar enormemente a las autoridades de competencia la imputación de las matrices de sociedades infractoras en expedientes sancionadores.

7. Finalmente, ya a partir del cártel internacional de la quinina sancionado por la Comisión en $1969^{8}$, la jurisprudencia también ha desarrollado el criterio de la "continuidad económica", según el cual "cuando una entidad que ha cometido una infracción de las normas sobre competencia es objeto de un cambio jurídico u organizativo, este cambio no produce necesariamente el efecto de crear una nueva empresa exenta de responsabilidad por comportamientos contrarios a las normas sobre competencia de la antigua entidad si, desde el punto de vista económico, existe identidad entre ambas entidades. En efecto, si las empresas pudieran eludir las sanciones simplemente por el hecho de que su identidad se hubiese visto modificada como consecuencia de reestructuraciones, cesiones u otros cambios de carácter jurídico u organizativo, se pondría en peligro el objetivo de reprimir los comportamientos contrarios a las normas sobre competencia y de impedir su repetición por medio de sanciones disuasivas".

Pues bien, sentadas estas bases, la cuestión suscitada en el asunto Skanska es si este principio de continuidad económica desarrollado jurisprudencialmente en el Derecho sancionador por infracciones de los artículos 101 y 102 TFUE es extrapolable a acciones civiles de daños y perjuicios.

\section{Los hechos del litigio nacional}

8. Las cuestiones prejudiciales planteadas por la sección civil del Tribunal Supremo finlandés se suscitan en un litigio entablado por el Ayuntamiento de Vantaa contra los partícipes de un cártel en el mercado finlandés del asfalto que había sido sancionado previamente por el Tribunal Supremo de lo Contencioso-Administrativo a propuesta de la autoridad de competencia finlandesa por infringir el artículo 101 TFUE. Antes de que se iniciara el procedimiento sancionador en 2004, las tres sociedades infractoras fueron adquiridas en el año 2000 por sendas sociedades ajenas al cártel (salvo la primera que también participó en el mismo y fue sancionada también como autora de la infracción). En aplicación de la antes descrita doctrina de la continuidad económica - las sociedades infractoras habían sido disueltas por sus adquirentes que, sin embargo, continuaron las actividades comerciales que les habían sido transferidas en el marco de los procesos de disolución voluntaria- el Tribunal Supremo contencioso administrativo impuso en 2009 sendas multas a las sociedades sucesoras (Skanska, NCC y Asfaltmix) de las tres infractoras.

9. Seguidamente, el Ayuntamiento de Vantaa interpuso una demanda de daños contra las tres sociedades sancionadas por el sobreprecio pagado por la realización de determinadas obras de asfaltado durante la vigencia del cártel. Las así demandadas se defendieron alegando que no eran responsables de los daños causados por las sociedades que habían participado en la infracción porque se trataba de sociedades jurídicamente autónomas y distintas de las demandadas.

10. No obstante, el tribunal de primera instancia que conocía del litigio estimó la demanda de daños por entender que, en aplicación del principio de efectividad del Derecho de la Unión, dada la disolución de las sociedades infractoras, resultaría imposible o excesivamente difícil obtener de éstas el resarcimiento de los daños sufridos por el cártel, de modo que debía aplicarse la doctrina de la con-

\footnotetext{
${ }^{7}$ Ver, por ejemplo, Sentencia de 29 de septiembre de 2011, Arkema, C-520/09 P, EU:C:2011:619 (98\%).

${ }^{8}$ Decisión de 16 de junio de 1969 (IV/26.623 - Acuerdo internacional de la quinina), OJ L 192, 5.8.1969, p. 5-22, ELI: http://data.europa.eu/eli/dec/1969/240/oj.

${ }_{9}^{9}$ Sentencia de 18 de diciembre de 2014, Parker Hannifin, C-434/13 P, EU:C:2014:2456, apdo. 40.
} 
tinuidad económica desarrollada por el TJUE en su jurisprudencia relativa al Derecho sancionador. Según esta doctrina, debía imputarse a las demandadas - las sociedades sucesoras sancionadas en vía contencioso-administrativa - la responsabilidad de indemnizar los daños causados de la misma manera que en materia de imposición de multas.

11. En segunda instancia, el tribunal de apelación anuló esta sentencia y desestimó la demanda por entender que el principio de efectividad del Derecho de la Unión no podía menoscabar el régimen finlandés de responsabilidad civil, rechazando que el criterio de continuidad económica pudiera extrapolarse del Derecho sancionador a las acciones por daños y perjuicios.

12. Finalmente, en casación, el Tribunal Supremo finlandés constató que el Derecho finlandés no establece normas para la imputación de la responsabilidad civil a terceros en situaciones como las del litigio en cuestión, puesto que se basa en el principio de que únicamente es responsable la entidad jurídica causante del perjuicio. La única excepción a dicho principio son los casos en los que la persona jurídica carece de autonomía porque las sociedades en cuestión hayan aprovechado la estructura del grupo societario para eludir dolosa o artificialmente su responsabilidad legal. Entendemos que se trata de supuestos análogos a los casos de "levantamiento del velo" en Derecho español.

13. Con referencia a las sentencias Courage/Crehan y Manfredi, que reconocen el derecho de "cualquier persona" a reclamar daños por infracciones de las normas de competencia del Tratado y que atribuyen al ordenamiento jurídico interno de los Estados miembros establecer las modalidades de ejercicio de este derecho, el Tribunal Supremo tiene la duda de si la imputación de la responsabilidad a las sociedades demandadas debe realizarse en aplicación directa del artículo 101 TFUE, y con qué alcance, o si debe realizarse en aplicación del Derecho finlandés. En este último supuesto con la duda añadida de si el principio de efectividad del Derecho de la Unión se opone a que el ordenamiento nacional limite esa responsabilidad a la persona jurídica causante del daño y, en caso afirmativo, si cabe supeditar la imputación de la responsabilidad a la sociedad sucesora a que ésta supiera o debiera haber sabido que la sociedad había cometido una infracción en el momento de adquirir el capital de esta última.

14. Ante estas dudas de interpretación del Derecho de la Unión y obligado como tribunal de última instancia por el artículo 267.3 TFUE, el Tribunal Supremo finlandés suscitó tres cuestiones de interpretación al Tribunal de Justicia. En primer lugar, si la cuestión de la imputación de la responsabilidad a la sociedad sucesora debía resolverse directamente por aplicación del artículo 101 TFUE o por el Derecho nacional. En caso de que fuera aplicable directamente el artículo 101 TFUE, el Tribunal Supremo pregunta, en segundo lugar, si el concepto de "empresa" desarrollado por el TJUE en el marco del Derecho sancionador — a saber, el concepto de "unidad económica" y el principio de "continuidad económica" - también es aplicable en demandas de daños por infracción de las normas de la competencia para determinar los sujetos obligados a tal indemnización. Y en tercer lugar, en el supuesto de que la cuestión de la determinación de la responsabilidad deba resolverse conforme al Derecho nacional, el Tribunal Supremo también quiere saber si el principio de efectividad se opone a que la sociedad sucesora de una sociedad infractora disuelta no responde aunque sea imposible o excesivamente difícil obtener indemnización de la sociedad disuelta. Y también si se opone a que el Derecho nacional exija que la reestructuración sea ilegal o artificial para eludir la responsabilidad o exija que la sociedad adquirente deba conocer o debiera haber conocido la existencia de una infracción en el momento de la reestructuración.

\section{La Sentencia del TJUE}

15. La sentencia del TJUE se limita a contestar a las dos primeras preguntas por entender que la determinación de la responsabilidad en el litigio nacional debe realizarse directamente en aplicación del artículo 101 TFUE y no del Derecho nacional. Esta respuesta a la primera pregunta del Tribunal Supremo sorprende, por cuanto el TJUE hasta ahora había reconocido siempre que las modalidades de 
ejecución del derecho de reparación de daños ex artículo 101 TFUE se rigen por el Derecho nacional y así incluso lo reafirma el Tribunal en el apartado 27 de la sentencia Skanska cuando señala que "Es cierto que, ante la inexistencia de una normativa de la Unión en la materia, corresponde al ordenamiento jurídico interno de cada Estado miembro regular las modalidades de ejercicio del derecho a solicitar la reparación del daño resultante de un acuerdo o práctica prohibidos por el artículo 101 TFUE, siempre que se respeten los principios de equivalencia y de efectividad (véase, en este sentido, la sentencia de 5 de junio de 2014, Kone y otros, C557/12, EU:C:2014:1317, apartado 24 y jurisprudencia citada)."

16. No obstante, la sentencia señala seguidamente que "la cuestión de la determinación de la entidad obligada a reparar el perjuicio causado por una infracción del artículo 101 TFE se rige directamente por el Derecho de la Unión"10. El razonamiento desarrollado por el Tribunal para explicar por qué una cuestión de legitimación pasiva se rige directamente por el artículo 101 TFUE es que el concepto de "empresa" para designar al autor de una infracción del artículo 101 TFUE está regulado en dicha disposición, que el Derecho de la competencia de la UE "tiene por objeto las actividades de las empresas" y que las infracciones a dichas normas tienen carácter personal, por lo que "incumbe a la empresa infractora responder del perjuicio causado por la infracción"11.

La sentencia rechaza el argumento de la Comisión de que del artículo 11.1 de la Directiva de Daños $^{12}$, que establece la responsabilidad solidaria de varias empresas que hayan infringido conjuntamente las normas de la competencia, se desprendería "que corresponde al ordenamiento jurídico interno de cada Estado miembro determinar la entidad obligada a reparar dicho perjuicio, de conformidad con los principios de equivalencia y de efectividad". El Tribunal señala que esta disposición no se refiere a la determinación de las entidades obligadas a reparar el daño, sino "al reparto de la responsabilidad entre dichas entidades, de modo que no confiere competencias a los Estados miembros para proceder a tal determinación" (apdo. 34). Añade, en cambio, que del artículo 1 de la Directiva sí se desprende que los responsables del perjuicio ocasionado por una infracción de las normas de la competencia son las "empresas" infractoras.

17. Al margen de que la Directiva de Daños no fuera aplicable a los hechos del litigio ratione temporis, como recuerda el propio Tribunal, la interpretación de ambas disposiciones nos parece acertada. De hecho, en las normas nacionales de transposición de la Directiva, como por ejemplo el artículo 71.2.b) de nuestra Ley de Defensa de la Competencia (LDC) ${ }^{13}$, la referencia a "empresas" en el artículo 1.1 de la Directiva sirvió para justificar la extensión de la legitimación pasiva en las acciones de daños también a las matrices de las sociedades infractoras. No obstante, que el legislador comunitario haya optado por ampliar el círculo de sociedades que deban responder a una acción de daños en el Derecho secundario no significa que este alcance de la responsabilidad ya se desprenda del propio artículo 101 del Tratado. La literalidad del artículo 1.1 de la Directiva de Daños también contrasta con el artículo 13.5 de la Directiva $\mathrm{ECN}+{ }^{14}$ que sí establece expresamente la aplicación de la doctrina de la continuidad económica por las autoridades nacionales de la competencia: "Los Estados miembros velarán por que, a efectos de imponer multas a sociedades matrices y a sucesores legales y económicos de empresas, se aplique el concepto de empresa."

18. De todo ello el Tribunal concluye que "las entidades obligadas a reparar el perjuicio causado por un acuerdo o práctica prohibidos por el artículo 101 TFUE son las empresas, en el sentido

${ }^{10}$ Apdo. 28.

11 Apdos. 29-31.

12 Directiva 2014/104/UE de 26 de noviembre de 2014, relativa a determinadas normas por las que se rigen las acciones por daños en virtud del Derecho nacional, por infracciones del Derecho de la competencia de los Estados miembros y de la Unión Europea, DO L 349, 5.12.2014, p. 1-19, ELI: http://data.europa.eu/eli/dir/2014/104/oj.

${ }^{13}$ Ley 15/2007, de 3 de julio, de Defensa de la Competencia, BOE núm. 159, de 4 de julio de 2007, ELI: https:/www.boe. es/eli/es/1/2007/07/03/15.

14 Directiva 2019/1 de 11 de diciembre de 2018, encaminada a dotar a las autoridades de competencia de los Estados miembros de medios para aplicar más eficazmente las normas sobre competencia y garantizar el correcto funcionamiento del mercado interior, DO L 11, 14.1.2019, p. 3-33, ELI: http://data.europa.eu/eli/dir/2019/1/oj. 
de esta disposición, que hayan participado en ese acuerdo o práctica." ${ }^{15}$ Con ello, el Tribunal rechaza el planteamiento de la Comisión y se inclina por la tesis del Abogado General Wahl de que la determinación de los responsables de resarcir los daños causados no constituye una modalidad de ejercicio del derecho indemnizatorio, sino un requisito constitutivo de la responsabilidad y, como tal, regulado por el propio artículo 101 TFUE y no por el Derecho nacional ${ }^{16}$. De no ser así, los requisitos de la responsabilidad no serían uniformes en los distintos Estados miembros (level playing field), lo cual daría lugar a la búsqueda de la jurisdicción más favorable (fórum shopping), según el $\mathrm{AG}^{17}$.

19. Una vez sentado que es el propio artículo 101 TFUE el que determina si la responsabilidad por una infracción de las normas de competencia puede imputarse a una persona jurídica distinta de la que cometió la infracción, el Tribunal de Justicia pasa a responder a la segunda pregunta del Tribunal Supremo finlandés: ¿es extensible el concepto de "empresa" desarrollado en la jurisprudencia de Tribunal en materia sancionadora, en particular el concepto de "unidad económica" y el criterio de la "continuidad económica" para determinar los sujetos obligados a indemnizar el daño en acciones civiles de resarcimiento de daños?

20. Tras recordar que el concepto de "empresa" en el artículo 101 TFUE comprende cualquier entidad que ejerza una actividad económica, con independencia de su naturaleza jurídica y de su modo de financiación y que "dicho concepto designa una unidad económica aunque, desde el punto de vista jurídico, dicha unidad económica esté constituida por varias personas físicas o jurídicas" (apdo. 37), el Tribunal pasa a recordar la doctrina de la "continuidad económica" desarrollada en su jurisprudencia en materia sancionadora. El principio general es el de responsabilidad personal, según el cual únicamente la "empresa" — en el sentido antes definido de "unidad económica", es decir, incluyendo matrices y otras sociedades del mismo grupo empresarial - que ha cometido la infracción puede ser declarada responsable de la misma en las decisiones sancionadoras de la Comisión. El principio de "continuidad económica" es una excepción a dicho principio que permite, excepcionalmente y en estrechos límites, imputar la responsabilidad por la infracción a una entidad distinta a la empresa que la cometió cuando la empresa infractora ya no existe como persona jurídica o deja de existir económicamente por haber cesado en el ejercicio de sus actividades económicas. En estas situaciones, el TJUE entiende que la imposición de una multa carecería de efecto disuasorio ${ }^{18}$.

21. Como recuerda la Sentencia ${ }^{19}$, cuando la empresa infractora ha dejado de existir por un cambio jurídico u organizativo, una reestructuración empresarial, la responsabilidad por la infracción puede atribuirse a la nueva entidad si, desde el punto de vista económico, existe identidad entre la antigua y la nueva entidad. En palabras del Tribunal, "imputar la responsabilidad de una infracción a una sociedad en su condición de sociedad absorbente de la sociedad infractora cuando ésta ya no existe no es incompatible con el principio de responsabilidad personal (sentencia de 5 de diciembre de 2013, SNIA/Comisión, C448/11 P, no publicada en español, EU:C:2013:801, apartado 23 y jurisprudencia citada)"”20.

22. La responsabilidad de una entidad distinta de la infractora ha sido reconocida en situaciones en las que la sociedad infractora es adquirida por un tercero ajeno a la infracción que posteriormente absorbe la sociedad adquirida, que deja de existir como persona jurídica. La justificación de extender la responsabilidad al adquirente en estos casos reside en que la sociedad absorbente adquiere los activos y pasivos de la infractora, incluidas sus responsabilidades derivadas de infracciones de las normas de la competencia. En estos casos, la sociedad absorbente suele continuar con el negocio adquirido, lo que,

\footnotetext{
15 Apdo. 32.

${ }^{16}$ Conclusiones del Abogado General N. Wahl, presentadas el 6 de febrero de 2019, Skanska, C-724/17, EU:C:2019:100, apdos. 59 y ss.

${ }^{17}$ Ibid., apdo. 67.

${ }_{18}$ Sentencia de 11 de diciembre de 2007, ETI y otros, C-280/06, EU:C:2007:775, apdo. 40.

${ }^{19}$ Apdo. 38.

${ }^{20}$ Apdo. 39.
} 
económicamente, justifica que también responda de las responsabilidades incurridas con ese negocio por el anterior titular del mismo.

23. Pero la cuestión prejudicial no versa sobre los requisitos de la doctrina de la continuidad económica, sino sobre si la misma, desarrollada como decíamos en el Derecho sancionador de la UE y concretamente a efectos de la imposición de multas a una sociedad sucesora en aplicación del artículo 23.2 del Reglamento 1/2003, puede aplicarse igualmente en supuestos de aplicación privada de las normas de competencia y concretamente a una acción de daños como la ejercitada por el Ayuntamiento de Vantaa en el litigio nacional. Las demandadas en el mismo lo negaban.

24. El Tribunal de Justicia, sin embargo, tras recordar que las acciones de daños, además de los procedimientos sancionadores administrativos, garantizan la plena eficacia del artículo $101 \mathrm{y}$ el efecto útil de la prohibición de acuerdos anticompetitivos que establece, respalda la extensión del principio de continuidad económica también a acciones civiles de reclamación de daños.

25. La Sentencia argumenta que también estas acciones civiles refuerzan la operatividad de las normas de competencia y pueden desalentar los acuerdos anticompetitivos. Tienen, por tanto, poder disuasorio, al igual que la imposición de multas en los procedimientos administrativos. Si las empresas infractoras pudieran eludir su responsabilidad mediante reestructuraciones empresariales, cesiones u otros cambios jurídicos u organizativos "se pondrian en peligro el objetivo perseguido por este sistema y el efecto útil de dichas normas"21. De ello concluye el Tribunal "que el concepto de "empresa», en el sentido del artículo 101 TFUE, que es un concepto autónomo del Derecho de la Unión, no puede tener un alcance diferente en el ámbito de la imposición por la Comisión de multas con arreglo al artículo 23, apartado 2, del Reglamento $n^{\circ} 1 / 2003$ y en el de las acciones por daños y perjuicios por infracción de las normas de competencia de la Unión" ${ }^{\prime 22}$.

26. Aunque el Tribunal deje, como corresponde en cuestiones prejudiciales, la apreciación final al Tribunal Supremo finlandés, ya anticipa que en el caso del litigio nacional las tres sociedades infractoras fueron adquiridas por las sociedades demandadas por el Ayuntamiento de Vantaa, que con ocasión de procedimientos de liquidación voluntaria llevados a cabo en 2000, 2001 y 2003, que se hicieron cargo de todas las respectivas actividades comerciales de las sociedades infractoras y las disolvieron. La Sentencia concluye que "En estas circunstancias, procede considerar que SIS, NCC y Asfaltmix, como respectivas sucesoras de Sata-Asfaltti, Interasfaltti y Asfalttineliö, han asumido la responsabilidad de estas últimas sociedades por el perjuicio causado por la práctica colusoria en cuestión, pues han garantizado, como personas jurídicas, la continuidad económica de las mismas", por lo que "las sociedades adquirentes pueden ser declaradas responsables del perjuicio causado por esa práctica colusoria", lo cual parece dejar poco margen al órgano jurisdiccional remitente para desviarse del pronunciamiento del Tribunal de Justicia.

27. Por último, la Sentencia rechaza la solicitud de una de las demandadas en el litigio nacional, formulada en la vista ante el Tribunal de Justicia, de que el Tribunal limitara en el tiempo los efectos de su sentencia, aplicando la nueva jurisprudencia sin efecto retroactivo. El Tribunal rechaza dicha petición por no cumplirse los estrictos requisitos de buena fe de los interesados y riesgo de trastornos graves, desarrollados en la jurisprudencia del Tribunal.

\section{Valoración}

28. El concepto de "empresa", así como la doctrina de la "continuidad económica" desarrollada en la jurisprudencia del TJUE en materia sancionadora ya había suscitado críticas por su posible

\footnotetext{
${ }^{21}$ Apdo. 46.

${ }^{22}$ Apdo. 47.
} 
incompatibilidad con el principio de responsabilidad personal, tal y como éste está reconocido en los ordenamientos jurídicos de los Estados miembros en Derecho penal y sancionador. En particular, la imposición de sanciones económicas a personas jurídicas que no han participado en la infracción ha suscitado dudas de constitucionalidad y compatibilidad con el principio de legalidad (nulla poena sine lege/culpa) garantizado en el artículo 47 de la Carta de Derechos Fundamentales y el artículo 6 del Convenio Europeo de Derechos Humanos (CEDH), donde esta jurisprudencia del TJUE aún no ha sido comprobada ni validada.

29. La extensión del principio de responsabilidad personal de la persona jurídica autora de la infracción - mediante su aplicación a la "empresa" en el sentido de los artículos 101 y 102 TFUE- a otras entidades (las matrices de las sociedades infractoras) sin expresa previsión legal, mediante desarrollo jurisprudencial, efectivamente suscita interrogantes desde el punto de vista de los derechos fundamentales garantizados en la Carta y el CEDH. Desde la sentencia Menarini ${ }^{23}$ del Tribunal Europeo de Derechos Humanos (TEDH) sabemos que los procedimientos sancionadores en materia de competencia tienen, por la enorme cuantía de las multas que imponen las autoridades de competencia, carácter penal y están, por tanto, sujetas a las garantías específicas en materia penal del artículo 6 del CEDH. E1 Tribunal justifica la responsabilidad de las sociedades matrices con que el principio de responsabilidad no se refiere sólo a la persona jurídica que cometió la infracción, sino a toda la "empresa", concepto que abarca a todas las sociedades pertenecientes a un mismo grupo empresarial.

30. El criterio de la "continuidad económica" da todavía un paso más en la extensión del principio de responsabilidad personal más allá del autor de la infracción, al extender la responsabilidad a terceros ajenos a la "empresa" infractora. Desarrollada como excepción a dicho principio, en la doctrina de la continuidad económica la imputación de la responsabilidad a un tercero se justifica por el hecho de que este último continúa con el negocio "infractor" y ha adquirido los activos y pasivos correspondientes al mismo.

31. Aunque es comprensible el objetivo de política de competencia de evitar que los infractores puedan eludir su responsabilidad sancionadora mediante reestructuraciones más o menos sofisticadas - como ocurrió en 2016 con la conocida como "Wurstlücke" (la laguna de la salchicha) en el cártel alemán de las salchichas, que en 2017 propició una modificación de la ley alemana contra prácticas restrictivas de la competencia (nuevos párrafos (3a)-(3e) del § $81 \mathrm{GWB}$ ) para evitar semejantes elusiones en el futuro- no lo es menos que estas excepciones al principio de responsabilidad individual de la empresa se aplican sin ninguna consideración de dolo o ánimo fraudulento de la empresa en cuestión; ni siquiera de conocimiento de la infracción en el momento de adquirir la sociedad posteriormente absorbida. Elementos que en cambio sí son relevantes y constitutivos de las excepciones reconocidas en los ordenamientos jurídicos nacionales para poder "levantar el velo" de una sociedad a modo de excepción del principio de responsabilidad personal de la persona jurídica autora de una infracción. En el asunto ETI, el TJUE incluso declaró, basándose en el efecto útil del Derecho comunitario de la competencia, que carecía de pertinencia que la transferencia de actividades no hubiera sido decidida por particulares, sino por el legislador con vistas a una privatización ${ }^{24}$.

32. Esta aplicación un tanto mecánica del principio de continuidad económica — cuya "importación" a la práctica de la Comisión Nacional de los Mercados y la Competencia (CNMC) ha sido avalada por nuestro Tribunal Supremo ${ }^{25}$ - contrasta con la más reciente práctica de la propia CNMC. En la resolución en el cártel de Montaje y Mantenimiento Industrial ${ }^{26}$, la CNMC analizó la aplicación del principio

\footnotetext{
${ }^{23}$ Sentencia del Tribunal Europeo de Derechos Humanos de 27 de septiembre de 2011, Menarini Diagnostics, 43509/08.

${ }^{24}$ Sentencia de 11 de diciembre de 2007, ETI y otros, C-280/06, EU:C:2007:775, apdo. 44.

${ }^{25}$ Sentencia del Tribunal Supremo de 16 de diciembre de 2015, recurso 1973/2014, ES:TS:2015:5531, confirmatoria de la multa impuesta a una de las empresas incoadas, en concepto de sucesora, en el marco del expediente S/0120/08 Transitarios.

${ }^{26}$ Resolución de la CNMC de 1 de octubre de 2019, Montaje y mantenimiento industrial, S/DC/0612/17.
} 
de continuidad económica a la sucesora de una sociedad que participó en el cártel sancionado en dicha resolución. Aunque se daban los requisitos de la doctrina, la CNMC llegó a la conclusión de que no procedía su aplicación a una sociedad sucesora que había adquirido los activos de la empresa infractora en un proceso de liquidación concursal. En efecto, conforme a la legislación concursal, la adquisición de varias unidades productivas, siempre con autorización del juez concursal, conlleva una sucesión de las deudas con los trabajadores y con la Seguridad Social pero no de otras. En caso de transmisión como un todo, la legislación incluso prevé, como incentivo, la exclusión de las deudas y gravámenes asociadas a tales activos. Merece ser reproducida en su literalidad la ponderación entre los distintos intereses en juego realizada por el Consejo de la CNMC: "Considera esta Sala que del análisis de la normativa concursal -que busca resolver una situación de insolvencia de un deudor para que pueda cumplir de la mejor manera posible con las obligaciones contraidas con sus acreedores- en relación con la doctrina jurisprudencial de la sucesión empresarial-que, con base en el principio del efecto útil, busca evitar la impunidad por la comisión de infracciones administrativas- se deriva una tensión que debe aclararse aplicada a este supuesto concreto. Ante la tensión mencionada, la aplicación de la jurisprudencia sobre el principio de continuidad económica y la normativa concursal al caso concreto no debe implicar en cualquier caso que la finalidad de la normativa concursal debe prevalecer sobre el efecto útil de la normativa de competencia, ni viceversa." ${ }^{27}$

33. Dado que en el caso concreto no mediaba fraude y el adquirente de los activos no tenía conocimiento de la existencia de una infracción de las normas de competencia cuando adquirió los activos (el procedimiento ante la CNMC se incoó después y también las inspecciones domiciliarias de la CNMC se realizaron con posterioridad a la compraventa), el Consejo de la CNMC resolvió — con un Voto Particular en contra que igualmente merece una lectura - no imputar al adquirente de los activos la responsabilidad por la infracción cometida por la empresa en concurso.

34. A la vista de la tensión entre buena fe y seguridad jurídica, por un lado, y el principio de efectividad en la aplicación del artículo 101 TFUE, por el otro, es de lamentar que el Tribunal de Justicia no tuviera que responder a la tercera pregunta del Tribunal Supremo finlandés, que planteaba precisamente estas cuestiones de dolo, fraude o al menos conocimiento de la sociedad adquirente, si la cuestión de la imputación de la responsabilidad a esta última se hubiera tenido que discernir conforme al Derecho nacional, aplicado dentro de los límites del principio de efectividad del Derecho de la UE. En el caso concreto, el procedimiento sancionador se había iniciado en 2004 con una propuesta sancionadora de la autoridad finlandesa de competencia ante los tribunales finlandeses, que en el sistema de dicho país deben imponer la sanción. Según la Sentencia del TJUE, las reestructuraciones y disoluciones de las sociedades infractoras se llevaron a cabo en los años 2000, 2001 y 2003, tras las adquisiciones de las mismas en el año 2000. No queda claro de la Sentencia del TJUE si en esos momentos los adquirentes ya tenían a podían haber tenido conocimiento de la existencia de una infracción del artículo 101 TFUE, a juzgar por las fechas señaladas y las preguntas del Supremo finlandés más bien parece que no.

¿Está realmente justificado que un adquirente de buena fe que absorbe la sociedad adquirida responda con su patrimonio de una infracción que desconocía en el momento de la adquisición de la sociedad que posteriormente resultó ser una infractora del artículo 101 TFUE? ¿Qué efectos tendrá esta jurisprudencia en procedimientos concursales, donde es el Estado - a través del juez concursal- el que autoriza al adquirente la adquisición de una sociedad o activos libres de cargas y gravámenes? Según la ya citada jurisprudencia ETI del TJUE, el conocimiento del adquirente no es relevante para imputarle la responsabilidad por una infracción latente, cuya existencia desconocía.

35. Estas preguntas, y alguna más, no encuentran respuesta en la Sentencia Skanska del TJUE que, sin embargo, agrava la responsabilidad de cualquier adquirente de buena fe, pues a partir de ahora no sólo podrá enfrentarse a la imposición de una multa por hechos que desconocía y en los que no participó, sino también a una avalancha de demandas de daños por hechos causantes desconocidos, en clara

${ }^{27}$ Ibid., p. 153. 
violación del principio de responsabilidad personal del autor de la infracción que hasta ahora regía en materia civil en los ordenamientos jurídicos nacionales.

36. Tampoco nos parece muy convincente que el principio de efectividad y el efecto útil del artículo 101 TFUE requieran esta extensión del principio de continuidad económica al Derecho civil de daños, como razona la Sentencia. En acciones consecutivas (follow-on) de daños, la empresa ya ha sido sancionada por infringir las normas de la competencia por una autoridad administrativa hasta un límite (el 10\% de su volumen de negocios) establecido por el legislador (art. 23.2 del Reglamento 1/2003 y sus equivalentes en los derechos nacionales). ¿El efecto disuasorio de las demandas de daños —en la que también hacía mucho hincapié el Abogado General Wahl en sus Conclusiones ${ }^{28}$-, realmente justifica este trato privilegiado de los acreedores perjudicados por infracciones del Derecho de la competencia frente a otro tipo de acreedores, por ejemplo, en materia de daños medioambientales o de responsabilidad por productos defectuosos? En nuestra opinión, la finalidad disuasiva también de las acciones de daños invocada en la Sentencia Skanska no debiera justificar una interpretación extensiva de los principios de causalidad y responsabilidad personal que rigen en los Derechos civiles de los Estados miembros. Y menos aun si la tendencia parece ser la interpretación extensiva del concepto de "unidad económica", como demuestra la reciente cuestión prejudicial elevada por la Audiencia Provincial de Barcelona en la que esta interroga al TJUE sobre si en aplicación de este concepto también cabe extender la responsabilidad de la matriz a la filial y no solo viceversa ${ }^{29}$.

37. En conclusión, la sentencia Skanska, además de suponer una notable incursión del Derecho de la UE en el Derecho civil de los Estados miembros, deja interrogantes.

\footnotetext{
${ }^{28}$ Conclusiones del Abogado General N. Wahl, presentadas el 6 de febrero de 2019, Skanska, C-724/17, EU:C:2019:100, apdos. $28-51$.

${ }^{29}$ Asunto C-882/19, Sumal/Mercedes Benz Trucks, DOUE C87/7, de 16.03.2020. No debiera prosperar esta interpretación extensiva, por cuanto la filial evidentemente no ejerce una "influencia decisiva" sobre su matriz que pueda justificar dicha imputación y porque no existe ninguna necesidad de dirigir las demandas de daños en el cártel de Camiones contra las filiales españolas de las matrices infractoras con sede en otros Estados miembros, cuando el propio Derecho de la UE proporciona los instrumentos procesales para notificar demandas a demandados radicados en otros Estados miembros.
} 